\title{
Bicycling and erectile dysfunction: A review of the literature
}

\author{
Ami Grunbaum ${ }^{1}$, Khaleeq-ur-Rehman MBBS Ms² ${ }^{2}$, Serge Carrier MD FRCSC ${ }^{3}$
}

\section{A Grunbaum, K-ur-Rehman, S Carrier. Bicycling and erectile dysfunction: A review of the literature. J Sex Reprod Med 2002;2(2):75-79.}

The bicycle is approximately 200 years old. The past several decades have borne witness to a booming interest in recreational and competitive cycling. According to recent estimates, there are more than 70 million bike riders in the United States alone.

This increasing participation in cycling deserves investigation of the potential traumatic and overuse injuries experienced by cyclists. Since 1975, there have been increasing numbers of published reports on the effect of bicycling on sexual function. In the present review, an overview of the relationship between bicycling and erectile dysfunction is presented. Proposed prevention and treatment strategies for erectile dysfunction among cyclists are reviewed.

Key Words: Bicycling; Erectile dysfunction; Perineal trauma

\section{Le vélo et la dysfonction érectile : Une analyse bibliographique}

RÉSUMÉ : Le vélo a environ 200 ans. L'intérêt pour le vélo récréatif et compétitif a connu une croissance explosive ces dernières décennies. Selon de récentes évaluations, on compte plus 70 millions de cyclistes aux États-Unis seulement.

Cet engouement croissant pour le vélo mérite d'être exploré afin d'évaluer les lésions traumatiques et de surmenage potentielles dont souffrent les cyclistes. Depuis 1975, de plus en plus de rapports ont été publiés sur l'effet du vélo sur la fonction sexuelle. La présente analyse présente un aperçu du lien entre le vélo et la dysfonction érectile. Les stratégies de prévention et de traitement proposées pour la dysfonction érectile chez les cyclistes sont examinées.
$\mathrm{T}$ he bicycle is approximately 200 years old, believed to have its origins in ancient China, Egypt and India (1). The past several decades have borne witness to a booming interest in recreational and competitive cycling. Racing, touring and off-road (mountain) bicycles have achieved growing popularity, both as means of transportation, as well as in recreational and competitive athletics. According to estimates, there are more than 70 million bike riders in the United States (2).
The increasing participation in cycling and its reported association with erectile dysfunction (ED) mandate that careful investigation of the potential traumatic and overuse injuries experienced by cyclists be performed. Case studies about biking and ED have been reported as early as 1975 (3). Since then, there have been increasing numbers of published reports in the forms of case studies, surveys and clinical investigations, describing a potential cause and effect relationship between bicycling and ED. In the pres-

\footnotetext{
${ }^{1}$ McGill University; ${ }^{2}$ Urology Research Laboratory, McGill University Health Center, Royal Victoria Hospital; ${ }^{3}$ Department of Surgery, Division of Urology, McGill University Health Center, Royal Victorial Hospital, Montreal, Quebec

Correspondence and reprints: Dr Serge Carrier, 687 Pine Avenue West, Royal Victoria Hospital S6.92, Montreal, Quebec H3A 1 A1.

Telephone 514-842-1231 ext 34302,fax 514-843-1552, e-mail serge.carrier@mcgill.ca
} 
TABLE 1

Summary of studies investigating erectile dysfunction, pudendal symptoms and bicycling

\begin{tabular}{|c|c|c|c|c|c|}
\hline Reference & $\begin{array}{l}\text { Number of } \\
\text { subjects }\end{array}$ & $\begin{array}{l}\text { Numbness } \\
\text { (yes/no) }\end{array}$ & $\begin{array}{c}\text { Erectile dysfunction } \\
\text { (yes/no) }\end{array}$ & $\begin{array}{l}\text { Erectile dysfunction } \\
\text { resolved (yes/no) }\end{array}$ & $\begin{array}{l}\text { Time to } \\
\text { resolution }\end{array}$ \\
\hline Silbert et al (4) & 2 & Yes & No & Yes & NR \\
\hline Amarenco et al (5) & 5 & Yes & No & Yes & Days to six weeks \\
\hline Goodson (6) & 1 & Yes & No & Yes & Four weeks \\
\hline Desai and Gingell (7) & 1 & Yes & Yes & Yes & Eight months \\
\hline Oberpenning et al (8) & 2 & Yes & No & Yes & Four and seven weeks \\
\hline McDonald (9) & 1 & Yes & Yes & Yes & One month \\
\hline Solomon and Cappa (10) & 1 & Yes & Yes & Yes & NR \\
\hline Ricchiuti et al (11) & 1 & No (pain) & No & Yes (temporarily) & NR \\
\hline Calvillo et al (12) & 3 & No & Yes & NR & NR \\
\hline Kita (13) & 1 & Yes & No & Yes & NR \\
\hline Golash et al (14) & 1 & No & Yes (priapism) & Yes & NR \\
\hline deRose et al (15) & 2 & No & Yes (priapism) & Yes & NR \\
\hline Andersen and Bovim (16) & 54 & Yes & Yes & Yes & Hours to months \\
\hline Schwarzer (17) & 1114 & Yes & Yes & NR & NR \\
\hline LaSalle et al (18) & 81 & Yes & Yes & NR & NR \\
\hline Nardozza et al (19) & 78 & No & Yes & NR & NR \\
\hline Renzuli (20) & 18 & No & Yes & No & NA \\
\hline
\end{tabular}

NA Not applicable; NR Not reported

ent review, an overview of the relationship between cycling and ED is presented, and prevention strategies and treatment options for cyclists with ED are discussed.

Over the past 25 years, there have been numerous case studies and surveys that have investigated ED and its related symptoms. These are summarized in Table 1.

\section{CASE STUDIES}

Silbert et al (4) reported the cases of two competitive cyclists (47 and 31 years of age). Both had numbness of the penis, and one also complained of an altered sensation of ejaculation and disturbances with micturition and defecation. Both patients' symptoms resolved after a period of abstinence from cycling, followed by alterations in saddle position and riding techniques.

Amarenco et al (5) reported the case of a 38-year-old man who complained of perineal hypoesthesia that slowly abated over a period of six weeks after a prolonged ride using a new saddle. The authors reported four other similar cases, arising after extended efforts (two patients) or after changing to a new saddle (two patients). These cases all resolved within several days.

Goodson (6) reported a case involving a 46-year-old man with numbness of the penile shaft after a prolonged ride on a narrow, hard, leather saddle. He regained sensation gradually over four weeks and has since used a wide, padded seat without the recurrence of symptoms.

Desai and Gingell (7) reported a 27-year-old man with ED and impaired penile sensation following a long ride on a narrow, hard, leather saddle. The patient had a complete resolution of symptoms after eight months.

Oberpenning et al (8) reported two cyclists who presented with decreased penile shafts and glans sensitivity. The first patient presented after an amateur bike race, and the second patient presented after a two- to five-day biking tour. In both cases, the genital hypoesthesia resolved after seven and four weeks, respectively, during which the patients strictly refrained from cycling.

McDonald (9) reported the case of a cyclist who complained of penile numbness following a long cycling effort, and his symptoms resolved only after the bike seat was lowered.

Solomon and Cappa (10) reported a 55-year-old man with a three-year history of riding a stationary bicycle. The patient experienced transient sensations of tightness around the glans penis while exercising. He also developed a progressive impairment of sexual function, to almost total impotence. The sensations of tightness resolved when he lowered the bicycle saddle. One month after the patient stopped bicycling exercises, his sexual function returned to normal.

The majority of the above reports concluded that the sensory changes were likely caused by perineal vascular compression. Because ED progressed gradually and resolved one month after cessation of riding, the sequence was suggestive of perineal nerve compression.

Ricchiuti et al (11) presented electromyographical evidence of bilateral pudendal nerve injury associated with excessive bicycling and an episode of perineal trauma in a 
44-year-old man. The patient complained of transient penile numbness and ED. The authors found that he had a prolonged pudendal nerve latency and a dispersed compound action potential. Erectile function and sensation returned to normal after the cessation of cycling.

Calvillo et al (12) reported a 52-year-old competitive cyclist with a two-year history of perineal and scrotal pain aggravated by sitting. A bilateral pudendal nerve block resulted in rapid analgesia and pain relief for $24 \mathrm{~h}$. This finding of pudendal neuralgia in an individual with a longstanding history of bicycling was strongly suggestive of a pudendal nerve injury secondary to nerve compression.

Kita (13) reported three healthy male cyclists $(54,33$ and 55 years of age) who developed ED. Radiological investigation demonstrated penile artery scarring that was hampering blood flow.

Golash et al (14) reported a 35-year-old amateur cyclist who sustained a blunt injury to the perineum after being thrown onto the handlebars of his mountain bike. He presented 10 days later with painless, high-flow priapism. An internal pudendal arteriogram revealed a laceration of the left cavernosal artery. The patient was treated successfully with percutaneous arterial embolization.

deRose et al (15) reported two cases (36 and 27 years of age) of blunt perineal trauma against the top tube of a bicycle. Both cases resulted in painless arterial priapism. Pudendal arteriography and colour Doppler ultrasound revealed the formation of an arteriolacunar fistula within the corpus cavernosum. Both patients were treated successfully with selective arterial embolization.

\section{SURVEYS}

Andersen and Bovim (16) conducted a survey of 160 male amateur cyclists (ages 23 to 54 years) following a $540 \mathrm{~km}$ touring race. Thirteen per cent of the cyclists reported temporary impotence, while $21 \%$ reported penile numbness. In $11(7 \%)$, ED lasted at least one week. In two men, it endured for five and eight months, respectively.

Schwarzer (17) conducted a study of 1114 amateur German male cyclists. Genital numbness, depending on their weekly training distances, developed in $58.3 \%$ to $70.3 \%$ of the cyclists. The majority of the cyclists had decreased sensation after 60 min of cycling and $4 \%$ reported impotence. In comparison, a group of swimmers had a $2 \%$ incidence of impotence without any reports of genital numbness.

LaSalle et al (18) evaluated 81 men (aged $41 \pm 11$ years) with ED. Eighty-four per cent reported that bicycling had resulted in at least one episode of perineal numbness or soreness. The subjects cycled an average of $142 \mathrm{~km} /$ week and $72 \%$ reported bicycling on narrow saddles.

Nardozza et al (19) conducted a questionnaire-based study comparing bicyclists, horse riders and runners. They found that cyclists presented with ED 80\% more frequently than did horse riders and runners.

Renzuli (20) reported 18 men with ED. They all had a history of blunt, traumatic perineal injury sustained while bicycling as children.

\section{NEUROVASCULAR ANATOMY AND VULNERABILITY}

The pathophysiology of genital numbness and ED in cyclists is not understood fully. Arguments have been made for nerve compression, arterial insufficiency and ischemic neuropathy. More likely, a combination of those processes is responsible. A basic knowledge of pelvic neurovascular anatomy is required to understand these underlying theories $(21-24)$

Somatosensory innervation to the penile region is transported along the pudendal nerve. The nerve arises from the sacral region of the spinal cord (S2-S4). The tract leaves the pelvis through the lower part of the greater sciatic foramen, and then travels through the lesser sciatic foramen to give off the inferior rectal nerve and enter the pudendal (Alcock's) canal within the obturator internus muscle. Toward the distal end of the canal, the pudendal nerve splits into the perineal nerve and the dorsal nerve of the penis.

The blood supply to the penis is derived from the paired internal pudendal arteries, arising from the internal iliac arteries. The pudendal artery exits the pelvis between the piriformis and coccygeus muscles by passing through the greater sciatic foramen. The artery then passes around the ischial spine and enters the perineum by way of the lesser sciatic foramen. The pudendal artery, nerve and vein pass through the pudendal (Alcock's) canal in the ischioanal fossa. The artery passes through the urogenital diaphragm and divides into four terminal branches - the bulbar, urethral, dorsal and cavernosal (deep) arteries.

It is not known where the neurovascular bundle is compressed, but the three most likely sites are inside the pudendal (Alcock's) canal, in the lesser sciatic foramen (when passing through), and against the arc, as the body is tilted forward on the saddle (10).

\section{CLINICAL INVESTIGATIONS}

Interest has focused on various bicycle saddle designs and their relationships to arterial perfusion and nerve conduction. However, physiological studies to evaluate these hypotheses have been limited.

The first clinical investigations of cycling-induced trauma and vasculogenic impotence date back to the early 1980s. Kerstein et al (25) measured penile systolic pressures using a digital blood pressure cuff before, during and after subjects sat on an unpadded bicycle saddle. Penile pressure after 5 min of sitting was $60 \%$ of baseline. There was a full return to normal after a $10 \mathrm{~min}$ recovery period.

Nayal et al (26) measured tissue oxygen tension of the glans penis in healthy men using a transcutaneous oxygen monitor. They demonstrated that glans oxygen tension was reduced by more than $68 \%$ from baseline after only 3 min of seated cycling. Again, there was a full return to normal values after a 10 min recovery period.

The same group later reported that cycling in a reclining position caused no alteration in penile blood flow (27). Of even greater interest was the demonstration that penile oxygen pressure while bicycling is significantly dependent 


\begin{tabular}{l}
$\begin{array}{l}\text { TABLE } 2 \\
\text { The effect of different saddle designs on glans tissue } \\
\text { oxygen tension during seated bicycling }\end{array}$ \\
\hline $\begin{array}{c}\text { Decrease of } \\
\text { initial penile } \\
\text { oxygen pressure }\end{array}$ \\
\hline Saddle type \\
$\begin{array}{l}\text { Narrow, heavily-padded seat } \\
\text { seat with groove in saddle nose }\end{array}$ \\
$\begin{array}{l}\text { Wide, unpadded, leather seat } \\
\text { Wide, medium-padded seat } \\
\text { without saddle nose }\end{array}$ \\
\hline $\begin{array}{l}\text { Adapted from reference } 28 \\
\end{array}$
\end{tabular}

on the type of saddle used (28). They reported that cycling on a saddle designed for women (wide, medium-padded seat without a saddle nose) reduced penile oxygen pressure by only $20.3 \%$, compared with $82.4 \%$ on a more traditional saddle (narrow, heavily-padded seat) (Table 2). They concluded that the most important factor in protecting penile perfusion is not the extent of padding, but the width of the saddle, with sufficient support to the pelvic bones to avoid compression of the perineal soft tissue.

Broderick (29) directly demonstrated decreased penile blood flow using duplex Dopplerometry on impotent men seated on different bicycle saddles after intracavernosal injections of prostaglandin $\mathrm{E}_{1}$. He found that a narrow, unpadded saddle reduced cavernosal arterial flow by $36 \%$, compared with a $17 \%$ reduction in those on a padded saddle.

Ricchiuti et al (11) demonstrated electromyographical evidence of pudendal nerve injury in an otherwise healthy bicyclist. They found that the 44-year-old man had a prolonged pudendal nerve latency along with a dispersed compound action potential.

We are currently developing an experimental model to noninvasively measure the relationship between bicycling and pudendal neurovascular function in healthy men. Our initial investigations confirmed the marked drop in tissue oxygen tension while astride the bicycle. We also successfully measured cavernosal arterial flows in healthy subjects and found a significant drop in blood flow. Our preliminary neural investigations demonstrated that the threshold of perception to a constant, direct electrical stimulus to the glans penis was raised significantly while astride the bicycle. We are presently investigating other modalities to increase our understanding of bicycling-related peripheral neuropathies (unpublished data).

\section{PREVENTION}

Intuitively, the area of contact between the bicyclist and the bike is the focus of the problem. There have been many marketed ergonomical saddle designs. Studies have noted that these ergonomical saddles are an improvement over narrow, unpadded saddles. However, wide, padded saddles were significantly less compressive of the perineal soft tissue than were the new designs $(28,29)$. Similarly, biking shorts with padded chamois increase comfort and may enhance protection.

In addition to the type of saddle, the saddle position is also important. The upward tilted seat places greater pressure on the perineum (9). However, an overly aggressive downward tilt would put undue stress on the shoulders and arms.

Cyclists should pay close attention to any early warning symptoms and signs, such as tingling or numbness of the penis. Even in the absence of such symptoms, cyclists should shift cycling positions periodically, rise out of the saddle and take breaks during long rides $(2,30)$.

\section{TREATMENT}

For the most part, men with some degree of discomfort and/or ED are best treated by conservative measures. This includes cessation of cycling, changing saddles and making adjustments in technique and bike setup. However, in cases of severe, intractable discomfort and/or dysfunction, more aggressive and invasive treatment may be required.

Amarenco et al (31) described several treatments for patients with perineal neuralgia:

- computed tomography (CT)-guided infiltration of the pudendal canal with corticosteroid;

- transcutaneous analgesic neurostimulation;

- clonazepam;

- radioisotope-guided infiltration of the pudendal nerve with corticosteroid plus lidocaine; and

- surgical release of the pudendal nerve

For all treatments, there was significant improvement of symptoms in $65 \%$ of patients (23\% complete improvement and $42 \%$ partial improvement).

Calvillo et al (12) used a CT-guided pudendal nerve block to temporarily relieve long-standing perineal and scrotal pain in a cyclist.

Shafik (24) diagnosed seven patients complaining of long-standing ED as having pudendal nerve compression. They were treated by surgical decompression of the pudendal nerve by freeing the neurovascular bundle from the pudendal canal. This led to improvement of ED in six of seven patients within six months.

In a separate study, Shafik (32) diagnosed pudendal artery compression in 10 patients complaining of longstanding ED. A similar procedure of pudendal neurovascular bundle decompression resulted in improved penile erections in eight of 10 patients within 12 weeks.

Shafik (33) has since improved on the technique and has successfully employed a laparoscopic approach to pudendal canal decompression. 
Several cases of high-flow priapism as a result of acute bilateral perineal trauma sustained during bicycling have been reported $(14,15)$. The patients suffered the injuries by being thrown against the bicycles' top tubes or handlebars. They were treated successfully with percutaneous arterial embolization.

\section{CONCLUSIONS}

A review of the literature supports a correlation between bicycling and ED. However, common sense and appropriate

\section{REFERENCES}

1. Mellion MB. Common cycling injuries. Sports Med 1991;11:52-70.

2. Cherington M. Hazards of bicycling: From handlebars to lightning. Semin Neurol 2000;20:247-53.

3. Bond RE. Distance bicycling may cause ischemic neuropathy of the penis. Phys Sports Med 1975;3:54-6.

4. Silbert PL, Dunne JW, Edis RH, Stewart-Wynne EG. Bicycling induced pudendal nerve pressure neuropathy. Clin Exp Neurol 1991;28:191-6.

5. Amarenco G, Lanoe Y, Perrigot M, Goudal H. Un nouveau syndrome canalaire: la compression du nerf honteux interne dans le canal d'Alcock ou paralysie perineale du cycliste. Presse Med 1987;16:399.

6. Goodson JD. Pudendal neuritis from biking. N Engl J Med 1981;304:365.

7. Desai KM, Gingell JC. Hazards of long distance cycling. BMJ 1989;298:1072-3.

8. Oberpenning F, Roth S, Leusmann DB, Van Ahlen H, Hertle L. The Alcock syndrome: Temporary penile insensitivity due to compression of the pudendal nerve within the Alcock canal. J Urol 1994;151:423-5.

9. McDonald DI. Is there life after genital numbness. N Z Med J 1987;100:465

10. Solomon S, Cappa KG. Impotence and bicycling. A seldom-reported connection. Postgrad Med 1987;8:99-102.

11. Ricchiuti VS, Haas CA, Seftel AD, Chelimsky T, Goldstein I. Pudendal nerve injury associated with avid bicycling. J Urol 1999;162:2099-100.

12. Calvillo O, Skaribas IM, Rockett C. Computed tomography-guided pudendal nerve block. A new diagnostic approach to long-term anoperineal pain: A report of two cases. Reg Anesth Pain Med 2000;25:420-3

13. Kita J. Hard ride: Some doctors think too much time on a bicycle seat causes impotence. Men's Health 1997;12:86-8.

14. Golash A, Gray R, Ruttley MST, Janikin BJ. Traumatic priapism: An unusual cycling injury. Br J Sport Med 2000;34:310-1.

15. deRose AF, Giglio M, DeCaro G, Corbu C, Traverso P, Carmignani G. Arterial priapism and cycling: A new worrisome reality? Urology 2001;58:462.

16. Andersen KV, Bovim G. Impotence and nerve entrapment in long distance amateur cyclists. Acta Neurol Scand 1997;95:233-40.

17. Schwarzer U. Genital numbness and impotence rate in long distance cyclists. The 94th Annual Meeting of the American Urological Association. Dallas, May 4, 1999. (Abst)

18. LaSalle MD, Wen C, Choi M, et al. You don't have to ride in the Tour de France: Erectile dysfunction in 81 consecutive riders. The precautions greatly reduce the risks and consequences. In the majority of cases, symptoms resolve within several months with conservative management. For severe, intractable cases of impotence and discomfort, interventional treatments have shown promise.

Conservative measures such as altering the seat position, increasing the width of the saddle, increasing the saddle cushioning, using cut-away designs to reduce perineal pressure, and elevating from the saddle during prolonged rides all seem like prudent measures to avoid cycling-induced ED. 94th Annual Meeting of the American Urological Association. Dallas, May 4, 1999. (Abst)

19. Nardozza A Jr, Claro JA, Oliveira FV, Aboim E, Lopes JA, Srougi M Does exercise-related perineal compression induce erectile dysfunction? The 95th Annual Meeting of the American Urological Association. Atlanta, April 29-May 4, 2000. (Abst)

20. Renzuli JF. Permanent erectile dysfunction: Should parents encourage their children to use wide seats and bicycles with top tubes. The 94th Annual Meeting of the American Urological Association. Dallas, May 4, 1999. (Abst)

21. Moore KL, Dalley AF. Clinically Oriented Anatomy, 4th edn. Baltimore: Lippincott Williams \& Wilkins, 1999.

22. Andersson KE, Wagner G. Physiology of penile erection. Physiol Rev 1995; 75:191-236.

23. Sharlip ID. Penile arteriography in impotence after pelvic trauma. J Urol 1981;126:477-81.

24. Shafik A. Pudendal artery syndrome with erectile dysfunction: Treatment by pudendal canal decompression. Arch Androl 1995:34:83-94.

25. Kerstein MD, Gould SA, French-Sherry E, Pirman C. Perineal trauma and vasculogenic impotence. J Urol 1982;127:57.

26. Nayal W, Schwarzer U, Klotz T, Heidenreich A, Engelmann U. Transcutaneous penile oxygen pressure during bicycling. BJU Int 1999;83:623-5

27. Sommer F, Schwarzer U, Graf C, Klotz T, Engelmann U. Changes in penile blood flow during cycling - how does one prevent a decreased perfusion? Dtsch Med Wochenschr 2001;126:939-43.

28. Schwarzer U, Klotz T, Sommer, F, Haupt G, Engelmann U. Cycling and penile oxygen pressure: The type of saddle matters. Presented at the 95th Annual Meeting of the American Urological Association. Atlanta, May 2, 2000. (Abst)

29. Broderick GA. Bicycle seats and penile blood flow: Does the saddle matter. The 94th Annual Meeting of the American Urological Association. Dallas, May 4, 1999. (Abst)

30. Biking and sex: Can riding cause impotence? Harvard Mens Health Watch 1999;3:6-8.

31. Amarenco G, Kerdraon J, Bouju P, et al. Treatments of perineal neuralgia caused by involvement of the pudendal nerve. Rev Neurol (Paris) 1997;153:331-4.

32. Shafik A. Pudendal canal decompression in the treatment of erectile dysfunction. Arch Androl 1994:32:141-9.

33. Shafik A. Endoscopic pudendal canal decompression for the treatment of fecal incontinence due to pudendal canal syndrome. J Laparoendosc Adv Surg Tech A 1997;7:227-34. 